\title{
Role of Pretreatment Option for the Membrane Based Water Purification System
}

Mohiuddin Md. Taimur Khan*

Department of Civil and Environmental Engineering, Washington State University, WA 99354, USA

Keywords: Coliform organisms; Concentration polarization; Chemical deterioration; Microfiltration; Ultrafiltration

\section{Introduction}

With the scarcity of water supply sources, many new water quality parameters came under consideration during purification. Those more stringent regulations lead to the conventional processes being replaced by advanced ones. Potable water quality monitoring parameters include coliform organisms, turbidity, dissolved minerals, disinfection by-product, toxic materials and specific inorganic and natural organic contaminants [1]. The term particles includes clays, algae, and other natural suspended particulate matter. There has been increased emphasis in developing the monitoring tools for detection of microbial pathogens including Giardia lambia, Cryptosporidium parvum (cyst of Protozoa), and viruses in potable water supply [2]. Water quality characterization is necessary to evaluate the biological and chemical safety of using source water for various applications and the effectiveness of individual treatment technologies. The degree of treatment required in individual water treatment facilities varies according to the specific reuse application and associated water quality requirements. Turbidity occurs when there are suspended solids (SS) in the water. SS is comprised of organic and mineral particles that are transported in the water column. Any pathogenic organism grows and builds its colony on/inside those suspended solids. Water contains many organisms, but all are not pathogenic. Growth and development of pathogenic organisms within the suspended solids are also questionable. It is well known that these are difficult to remove by the conventional drinking water treatment process of coagulation-sedimentation followed by rapid sand filtration [3]. Membrane technologies have become increasingly popular in water and wastewater treatment applications for a variety of reasons.

These are

(1) Prospect of more stringent water quality regulations,

(2) Inadequacy and deterioration of existing water resources,

(3) Greater emphasis on water reclamation and reuse,

(4) Lower capital requirement because less land is required, and

(5) Decline in operation and maintenance costs resulting from research, development, and consequent advances in membrane technologies [4]

Only the higher-pressure membrane processes such as nanofiltration (NF) and reverse osmosis (RO) can remove dissolved organic matter, such as, humic substances and taste and odor producing compounds, as well as synthetic organic compounds such as the trihalomethanes (THMs) to a significant degree. But what if these organic materials could be associated with a particulate phase, for example, with powdered activated carbon (PAC)? It should, then, be possible to use the lower-pressure (and lower operating cost) membrane processes such as microfiltration (MF) and ultrafiltration (UF) to remove natural particulate matter, PAC, as well as the organics adsorbed on the PAC
[5,6]. PAC in several occasions are produced from wood in the form of sawdust. The particle size of PAC assures that intraparticle diffusion will not be the rate-limiting step. Thus the adsorption operation is designed from the viewpoint of selection of contacting apparatus, mixing of PAC with liquid, the separation of PAC after contacting and disposal or regeneration if possible after usage [4].

A serious problem regarding membrane technologies that undermines their economics is the deterioration of permeate-flux with operation time. This flux depression may be attributed to a number of factors such as membrane fouling, concentration polarization, changes in membrane properties, and changes in the properties of the feed solution. Changes in membrane properties are due to mechanical compaction or creep (caused by application of high pressures), or to chemical deterioration. The term membrane fouling refers to pore plugging and external pore blocking resulting from deposition of submicrone-sized suspended particles and colloids on the membrane surface, precipitation of relatively smaller solute species within the membrane pores and on the surface, or both. Such fouling often leads to an irreversible flux decline during various stages of the filtration, depending on the fluid and membrane characteristics. On the other hand, the concentration polarization refers to the formation of a gel layer on the membrane surface. This gel layer is formed by the deposition of larger organic molecules such as those of natural dissolved organic matter (DOM), resulting in a localized increase in organics concentration at the membrane surface.

Concentration polarization effects are generally reversible upon cleaning the membrane and can be reduced by lowering the concentration of organic compounds contributing to it. Membrane cleaning generally reduces the effects of fouling and concentration polarization. Occasionally, the use of MF or UF in conjunction with granular activated carbon (GAC) is suggested. However, on reflection, this does not seem to be an efficient use of either the membranes or GAC. For example, if the GAC columns preceded the membrane and the raw water was directly applied to the GAC, the GAC surfaces would be fouled rapidly. On the other hand, if the GAC columns followed by the membrane, the superior disinfection capabilities of the membrane process could very likely be compromised, due to biological growth on the carbon.

${ }^{*}$ Corresponding author: Mohiuddin Md. Taimur Khan, Department of Civil and Environmental Engineering, Washington State University, WA 99354, USA, Tel: 406-579-4757; E-mail:m.khan@tricity.wsu.edu

Received January 12, 2015; Accepted January 23, 2015; Published January 26 2015

Citation: Mohiuddin TK (2015) Role of Pretreatment Option for the Membrane based Water Purification System. J Membra Sci Technol 5: e121. doi:10.4172/2155 9589.1000e121

Copyright: $\odot 2015$ Mohiuddin TK. This is an open-access article distributed under the terms of the Creative Commons Attribution License, which permits unrestricted use, distribution, and reproduction in any medium, provided the original author and source are credited. 
Citation: Mohiuddin TK (2015) Role of Pretreatment Option for the Membrane based Water Purification System. J Membra Sci Technol 5: e121. doi:10.4172/2155-9589.1000e121

Page 2 of 2

\section{Conclusion}

Hybrid membrane technologies are entering the mainstream for drinking water treatment because of the increased stringency of water quality standards, increasingly restricted water sources and supplies, and their more competitive cost. PAC reduced the effects of membrane fouling even after the larger particles had abraded to much smaller sizes, causing higher TMP and increasing the fouling frequency. In the presence of PAC, smaller particles did not play an important role in membrane fouling. Moreover, continuous air scrubbing inside the membrane bioreactor (MBR) reduced the formation of cake on the MF surfaces. Higher accumulations of SS and the gradual incremental accumulation of finer particles were observed in the system without PAC. PAC particles in the reactors enhanced the disaggregation of SS. The presence of PAC inside the MF MBR system improved filtration performance and lowered the impact of organic carbon, carbohydrates, polysaccharides and proteins on membrane fouling. Major portions of the polysaccharides were biodegraded inside the MBR. Protein effects on membrane fouling rate were more prominent than polysaccharides; however, the presence of PAC enhanced the biodegradation of both proteins and polysaccharides.

\section{References}

1. Khan MMT, Lewandowski Z, Takizawa S, Yamada K, Katayama H, et al. (2009) Continuous and efficient removal of THMs from river water using MF membrane combined with high dose of PAC. Desalination 249: 713-720.

2. Asano T (1998) Wastewater Reclamation and Reuse. Water Quality Management Library, Volume 10, Technomic Publishing Company.

3. Kim H, Nishijima W, Shoto E, Okada M (1997) Pilot plant study on ozonation and biological activated carbon process for drinking water treatment. Water Sci Technol 35: 21-28.

4. Khan MMT, Takizawa S, Lewandowski Z, Jones WL, Camper AK, et al. (2011) Membrane fouling due to dynamic particle size changes in the aerated hybrid PAC-MF system. J Membra Sci 371: 99-107.

5. Clark MM (1992) Ultrafiltration of lake water: Optimization of TOC removal and flux; Chap.23 in Influence and removal of organics in drinking water; Lewis Publishers.

6. Khan MMT, Takizawa S, Lewandowski Z, Rahman MH, Komatsu K (2013) Combined effects of EPS and HRT enhanced biofouling on a submerged and hybrid PAC-MF membrane bioreactor. Water Resear 47: 747-757. 